\title{
Analysis of Change Within and Between Firms embedded in their environment in the context of increasing interactions: understanding complexity of organizations
}

\author{
PAUl Bouvier-PATRON*
}

\begin{abstract}
The theory of firms and organizations is at the heart of the economic dynamics analysis because of increasing and evolving interactions within the concrete industrial organization, at intra and inter firm(s) levels. At first, we present (Sect. 2) the evolution of the theory of the firm and of organizations renewed by the complexity approaches, then (Sect. 3) we study the conditions of change within a single organization or a set of organizations before, finally (Sect. 4), putting into perspective authors' contributions to this special issue.
\end{abstract}

\section{Introduction}

The theory of firms and organizations is at the heart of the economic dynamics analysis because of increasing and evolving interactions (within the concrete industrial organization, at intra- and inter-firm levels) with the environment: competitive through the adoption of rival technological options (Auriol and Benaïm, 2001), spatial and temporal (Zimmermann, 2001), decisional (Le Bas, 2001), structural where organizations cope with contingencies (Poncet, 2001) and, in the last case, specifically with the now important role played by product customizing as a stimulus for organizations coming from the demand side (Harkema and Baets, 2001). Centered on the complexity analysis (Paulré, 1999b), our contribution (Introduction of this special issue) proposes a large illumination of the theoretical landscape related to economic dynamics and intra- as well as interorganizational changes.

First, we will present (Sect. 2) the evolution of the theory of the firm and organizations renewed by the complexity approaches, then (Sect. 3) we will study the conditions of change within a single organization or a set of organizations before, finally (Sect. 4), putting into perspective authors' contributions to this special issue.

\footnotetext{
* Coordinator of the present issue and associate-member of Y. SY. S., Paris I Pantheon Sorbonne. E-mail: tauveron@edpsciences.org

Keywords: complexity, interactions, intra- and inter organizational changes, theory of the firm.
} 


\section{Evolution of firm and organization theories renewed by the complexity approaches}

To move away from the sterility of debates, when only ideological and of opposing types, the new exploration suggested in social sciences seems to be quite promising throughout the Complexity Sciences of which Simon $(1947,1980,1982)$ is one of the great architects and developers.

The new approaches are aiming, in the framework of the theories of complexity, to understand differently economics and management sciences within the field of firm dynamics and with more open tools than the old ones even if they have been borrowed, as well as the old ones, outside of Social Sciences.

Naturally, the field which could possibly be covered to envisage new angles of analysis and with the help of tools that are linked to new approaches, is huge and we propose to explore a necessarily restricted field: that of the firm and its environment or rather, to avoid misunderstandings, the firm in interaction with other firms in a given environment.

This interactive dimension cannot be thought of in a static way and must be based on a dynamic reasoning where the learning and changing dimensions all take their place.

If it is necessary to take interactions into account (in particular relationships between organizations), it can no longer be done with an analysis linked to a given framework (standard or evolutionary) and also deterministic (mechanistic process with the standard theory, environment selection in the evolutionary theory).

It is necessary to integrate elements of complexity. That is the only way to be able to resolve questions like the one related to stability (very useful for the making of value) to a given point... Is it determined (by inertia and/or dependency on the past, Arthur, 1989) or completely free? A given trajectory, in a dynamic framework, is it foreseeable or not?

To try to answer it, it must be highlighted that (Simon, 1980, pp. 52-57) the process of evolution leads to global qualitative leaps from simultaneous adaptations of each basic element.

However, that is only possible because stable principles exist which assure and preserve the potentiality of this evolution: it is about, for example, genes in biology ${ }^{1}$. In economics and in management sciences, finding the equivalent principle is very hard but it could be about markets (which are always regulated in one way or another, including when there are evolutions often considered as crises) and organizations (this is what Simon, 1980, p. 61 seems to suggest to us).

It must not be forgotten that Simon (1980, pp. 48-50) absolutely refuses, as well as Powell (1990), the Market-Organization dichotomy ${ }^{2}$. This gives an extra warning, if

\footnotetext{
${ }^{1}$ Simon (1980, p. 56). Furthermore, Simon (1991, pp. 34-37 and 1993) focuses, above all, on the resistance factors, stabilizers and/or altruistic behaviors which stabilize the ecological milieu and do not generate a global equilibrium of populations based on individuals and selfish behaviors (which is generally preferred in economics).

${ }^{2}$ Contrary to an idea which made its way in economics and management sciences after Williamson (1975, 1985) took and systematized Coase (1937). One can refer to Bouvier-Patron (1993) for a presentation of the whole question.
} 
there is a need for it, about the importance of inter-firm coordination and the role played by these kind of ties in understanding complexity in the economy.

In a dynamic framework where interactions are increasing between actors, within organizations and between organizations, the configurations of coordination are renewed through branching off. The most crucial point was to put forward a dynamic theory of organizations (cooperating at Ring and van de Ven, 1992 and 1994, but not necessarily ${ }^{3}$ ) where interacting, self-organization and learning play an important role.

Opportunities are built internally and also "supplied" by the environment and, independently of the weight of the past and chosen directions, the capacities of firms to move to a new market position and/or catch new opportunities can only be envisaged with open organizations which take into account the renewal of competencies and learning.

Interactions, the nature of interactions, the capturing of outside opportunities, path dependency, renewal of competencies, and learning are key factors for the study of the economy dynamics.

The narrow overlapping between the necessary principles of stabilization to make organizations able to run and of dynamic to make organizations evolve must lead to a rereading of the theory of the firm. The arbitration that has to be achieved is done by looking at it in two ways (apparently contradictory) that one can sum up by the stability/ dynamic duo. This has to be linked back to Weick's intuition (1979, p. 215) for whom the requirements of the working of a firm imposes that an arbitration must be found between flexibility and stability. Let's see how it works...

According to Simon's ${ }^{4}$ Procedural Rationality (within the framework of bounded rationality), it is important to underline the fundamental role played by the stabilization of the environment process ${ }^{5}$ as well as moments of (temporary) rest between two "research procedures" or "searches" launched by a firm when one accepts the idea that the firm is under a limited rationality of actors (actors being firms and/or firms' members instead of agents in the standard approach). The precision concerning stabilization has a great importance in explaining how firms are creating values (Bouvier-Patron 1992, 1996a, 1996b, 1998a, 1998b, 1999) because by sometimes focusing on the sectors of the economy where actors deal with rapid evolutions and where sectors are always unbalanced, one comes to think there is a perpetual "search". First of all the existence of a "search" must not be overwhelmed with the stating of a proof according to which it is not possible to predict, locally or in the aggregate, the future behavior of an economic system even if one tries to construct possible scenarios. Next, it is even more important to remember that the fixing of objectives, achieving these objectives as well as their eventual reviewing is the unquestionable phenomenon of human activity necessitating the building up of expectations (as well as conjecturing on the future) and this attitude will be a part of what tomorrow will be made of.

\footnotetext{
${ }^{3}$ Which comes back, in the static and non-cooperative context, to more classical debates opposing market and organization like Imai and Itami (1984).

${ }^{4}$ For a presentation, see Bouvier-Patron (1998a).

${ }^{5}$ Simon (1958, pp. 389-392) underlines the role of institutions in stabilizing the environment.
} 
Also, the combination of the firm and change seems to be inextricable and gives the coherence of the demonstration proposed which is based on two principal axes:

- Change and organizational learning are taking up an increasingly large place in the literature on economics and on management sciences (for a presentation see, respectively, Paulré, 1993 or 1997 on one hand and Guilhon, $1998^{6}$ on the other).

- The firm's field (as well as Industrial Organization), is a less consensual positioning but relatively coherent with the previous field and perfectly legitimate if one accepts the idea that firms are central elements of the contemporary economy (Jacquemin, 1985 and 1988; Tirole 1988; Holmstrom and Tirole, 1989).

The orientation proposed here is to explore change within and between firms with the help of complexity approaches. We will then examine the evolution of the Industrial Organization analysis through ( $c f$. Sect. 2.1) the questioning of the standard approach in economics as well as ( $c f$. Sect. 2.2) the present anchorage point of the theory of the firm before taking into account ( $c f$. Sect. 2.3) recent contributions of Complexity Sciences to the theory of the firm and organizations.

\subsection{Questioning of the standard approach: revolutionizing or reforming?}

One will firstly (Sect. 2.1.1) present the first effective attempt to elaborate an alternative paradigm to the standard approach and (Sect. 2.1.2) give some hints about possible ways of reforming the standard approach.

\subsubsection{Revolutionizing: looking for a substitute to the standard approach}

It is necessary to deplore two major deficits of the standard approach (or of reference): - in the treatment of coordination as well as interactions between actors (individuals or organizations; and this is included in the context of the games theory used and developed a lot more to look for unique and stable equilibrium than for forming and using tools for analyzing real behaviors and exploring truly strategic interactions);

- in the analysis of the working and of the life of organizations... Indeed, an organization is born, lives and dies in a temporality which is more or less long. It is a central point of economic life that standard theory seems to ignore, but only taking into account the affirmation that firms maximize their profits (at a partial equilibrium or, all together, at a general equilibrium) in the short run and sequentially by respecting this rule all the time. In order to bring coherent answers within the heart of a single paradigm, an initial solution (as a substitute for the standard approach) was proposed by the evolutionary theory (or evolutionism) thanks to Nelson and Winter. The evolutionary theory (of which two principal roots come from Schumpeter and Penrose) unquestionably represents, since the famous publishing of Nelson and Winter (1982), an alternative paradigm of the standard theory.

\footnotetext{
${ }^{6}$ For a synthesis paper of ideas, this last reference is valid under the condition that it does not necessarily follow the way of the indicated progress according to which voluntary strategies of planned changes should be favoured.
} 
It is generally accepted that the aim of the evolutionary theory is the analysis of technical change. From the beginning, two key arguments have been put forward to explain evolution and changes:

- individual behavior (then on the next level, the inter-individual interactions) is based on "satisfactory aspiration level" (related to Simon's "Satisficing" 7 rather than optimization) as well as on routines;

- the survival of a firm on the market is grounded on dynamics out of the equilibrium (behaviors not being controlled by the rule of profit maximization).

To put it another way, it concerns two breaking points with the standard theory and two crucial points to develop a new analysis.

Nelson and Winter (1982) underline, after March and Simon (1958) and Polanyi (1966), the role played by routines and on the tacit nature of knowledge for firms in order to innovate. It is a double argument whose relevancy is more and more essential today. Paradoxically perhaps, it is also the treatment of routines which is a serious limitation of what has been proposed by Nelson and Winter:

- interactions are simply ignored (i.e. locked in the black box of prevailing routines);

- all significant intra-organizational conflict is kept within a restricted area and follows a given path coherent with the current routine ${ }^{8}$.

Thus, the dimensions of strategic interactions and conflicts are, finally, ignored. In the framework of the evolutionary theory, applicable to populations, are preferred the general principles of selection (selection process which comes exclusively from the environment; from that, the induced causality takes us, onto the organizational level, to the most crude contingency theory) and of adaptation (individuals in organizations are walled into their firms and within routines in the framework of a given trajectory). Therefore, the evolutionary paradigm as it is (even by putting forward that it is not a finished theory) ignores the question of the degrees of strategic liberty and the analysis of conflicts.

One has, in economics or in management sciences, no more reason to satisfy an analysis of mechanical inspiration, as is the standard framework, than an analysis of biological inspiration. It is particularly regrettable that the evolutionary theory suggests that individual freedom will vanish for the benefit of naturalist logic in terms of species; the biological robots of the evolutionary theory would then replace mechanical robots of the traditional theory, both ignoring the importance of strategic interactions (pre-eminent in reality and what should also be the case in theory).

In this way, the evolutionary and standard paradigms make up useful guidelines for analysis without always being very convincing (Bouvier-Patron, 1999; Paulré, 1999a): it must be considered as an ambitious but incomplete and imperfect attempt. However, within the evolutionary paradigm, the most important point is the explicit acknowledgement of a growing number of authors of a higher validity, in economics, of the Lamarckian

\footnotetext{
${ }^{7}$ Simon (1979, p. 503) and Simon (1980, p. 36).

${ }^{8}$ Nelson and Winter (1982, p. 110): "Manifest conflict follows largely predictable paths and stays within predictable bounds that are consistent with the ongoing routine".
} 
hypothesis with regard to the Darwinian hypothesis about evolution ${ }^{9}$ : intentional actions and strategies must play the role deserved them.

\subsubsection{Reforming and transcending the standard approach}

The standard approach (or of reference) was renewed only recently by the theory of imperfect competition (whose roots are, however, very old: Cournot, 1838): that is to stress the point about market failures and/or imperfections (towards, especially, asymmetries of information thanks to Akerlof, 1970) but, finally, explaining the organization by reducing it to the individual behavior of maximization. And that, in the best instance, by using the theory of contracts (of the first or second rank) in the context of the agency theory ${ }^{10}$ where rules (but never strategies or behaviors) ${ }^{11}$ are examined to study problems of moral hazard and adverse selection (Laffont, 1985). If a lot of situations can be treated in this way (but still according to some very restrictive assumptions), a lot of other situations do not and cannot.

At this stage, as it very often the case, arguing about what has been forgotten and unexplained within economics to an impossibility or a prohibition of disciplinary overstepping is not acceptable. For instance, are we supposed to say that the theory of organizations is outside the field of relevancy of economics? Simon (1947) gave fortunately a negative reply to this question and, by later reinforcing its approach, opened the way to a better building up of an economic and managerial theory of organizations (Labourdette, 1992), moreover a lot more productive than that linked to Williamson ${ }^{12}$ neo-institutionalism simplifications.

It shows a serious weakness that could be exploited on a long-term basis to face a break of paradigm and constitute possible alternatives for the standard paradigm. Coase (1937) had originally shown the role played by incomplete contracts: even today, it remains an open paradigm. A paradigm explored by Williamson and, on a larger scale, the neo-institutionalism wave which, by the way, borrows innovative and autonomous work like that of Schelling $(1956,1960)$ : Schelling then had taken the problem one step further by proposing, using metaphorically, a relational model with "hostages" and "hold-up". The partisans of the standard approach have since replied to this challenge because the gap noted in the analytical edifice was too great (the reply put forward, relatively recently, is still only an outline: the difficulty in writing a contract must lead to internalization, Grossman and Hart 1986, Riordan 1990). At the same time, it is a promising piece of work in hand and works like those of Hart and Moore (1990) raise the keenest interest. In this last reference which is quite innovative, the definition of "essential assets" and the question of replacement ("dispensable" or not) of essential

\footnotetext{
${ }^{9}$ Saviotti (1996, p. 36): "Firm Strategy and search activities imply a degree of intentional behaviour in the presence of uncertainty. While it is true that the outcomes achieved differ, sometimes considerably, from the goals pursued, it is also true that ex ante adaptation of firms to their external environment to firm requirements are essential components of firm behaviour".

${ }^{10}$ For a good presentation of this theory, Sappington (1991) and Charreaux (1987).

${ }^{11}$ This is why non-cooperative games theory is the other powerful vector of progress: the economic agents thus become actors, or players, whose strategic role is restored (not in a very satisfactory manner but, at least, partially) contrarily to contractual situations within agency theory where strategies are ignored.

${ }^{12}$ For a presentation, Ménard (1990); for a distant point of view, Bouvier-Patron (1992, 1993).
} 
assets are at the heart of the current debate on firms. Surprisingly, it is interesting to note that one goes back to the intuitions of Richardson (1972) which, from common sense and without analytical tools, showed the importance of the debate on complementary activities (versus similar) to remelt the analysis of the Industrial Organization (and of relationships between firms) and help us to think, finally, of the firm as it is. Other complementary work, like that of Teece $(1980,1988)$, Dosi et al. (1990), Prahalad and Hamel (1990) have stressed the importance of "key competencies" which firms have: to think and strategically define what the "Core Business" is, to elaborate the global strategy as well as the evolution of the firm.

More recently, the interrogation has been focused on the question of the renewal of competencies (Doz, 1994) ${ }^{13}$. However, it involves a question that has already been asked through the co-existence of several activities within the firm and where these secondary activities (but generally complementary to the principal ones) tend to serve as a leaning point to gradually develop a new kind of core for the firm. Weick (1977) was the first to put forward the importance of secondary activities (secondary, that is to say away from the core of the firm) as a way of improving and/or provoking the evolution of the competencies as well as the capacities of a company to answer complexity and changes. Dosi et al. (1990) have explored particularly well this process in its dynamics.

Moreover, non-reversibility is a crucial point not to be scorned; especially through the concept of path dependency (Arthur, 1989). Non-reversibility (mainly related to historical time and decisions) is a key variable for explaining trajectories and is not (or is no longer) a monopolistic concept of the evolutionary theory. Indeed, the phenomenon of individual reputation (Selten, 1978; Kreps and Wilson, 1982; Milgrom and Roberts, 1982; Axelrod, 1984) is omnipresent today in micro-economics; these phenomena are now integrated even though they often contradict predictions in order to reach equilibria such as the traditional standard theory could provide. Some kind of relativism on this result is required because the restriction related to a reputation effect is weak compared with that which goes along an irreversible process (and necessarily too in an irrevocable one) as proposed by Georgescu-Roegen (1971). In such a perspective, path dependency is an interesting basis for contemporary analysis (but it would be illusionary to see in it only determinism since the economic world is open and new opportunities allow old or new firms to respond and achieve good positioning).

The organization should at the same time be thought of in its static and dynamic dimension and one does not exist without the other. This stability/dynamic duo is crucial (Weick, 1979, p. 215). The economic universe is changing but, at the same time, internal and external coordination, responsibilization and the building up of competencies, rather than divination, appear as key factors of success in stabilizing the environment and reaching fixed objectives.

Further upstream and more basically, as we have already shown (Bouvier-Patron, 1999), the coordination of knowledge, actors, activities, competencies and organizations ${ }^{14}$

\footnotetext{
${ }^{13}$ Doz (1994) for a very complete survey on the concept of competence and Durand (2000) for a work more exclusively centred on management sciences.

${ }^{14}$ Economics and management sciences are taking into account, more and more, the cooperative dimension between organizations: the question of the coordination of a multiplicity of organizations is then essential.
} 
is grounded on the building up of a common knowledge (which is necessary to mobilize the individual competencies so as to build a core business), within an organization or a set of organizations, and is based upon four dimensions:

- the existence of private information which is useful to the group: Hayek (1945) is the promoter of the specificity and idiosyncrasy of knowledge and of the role of an organizational weld giving to each individual the chance to reveal to a given collective body, against incentives, his private knowledge (the theory of contracts is essential here but not sufficient);

- the tacit and explicit nature of knowledge (Polanyi, 1966) and of competencies (Teece, 1980 and 1988; Dosi et al. 1990);

- the requirement to reduce the uncertainty (Knight, 1921), thanks to the organization, in order to, in a non-reversible temporality, combine the elements (at individual as well as collective levels) of knowledge, of know-how, of techniques and of competencies as well as building up and using (and/or, when it is possible, capturing ${ }^{15}$ ) the new information, the new knowledge, the new know-how or the new competencies;

- the working or the creation of institutions when $n \geq 2$ ( $n$ individuals or $n$ organizations) to deal with what is, however, not understandable to human society: Knight (1921), Simon (1958) and Bouvier-Patron (1992, 1999).

\subsection{Present anchoring point of organization dynamics and of theory of the firm}

The roots of the theory of the firm are already old. However, since the former Cournot's fruitful approach (1838) ${ }^{16}$, other complementary contributions (mentioned below) are of great interest:

- (a) Knight (1921) on the capacities of deciding the face of uncertainty and on the basis for understanding nowadays theory of firms and organizations.

\footnotetext{
${ }^{15}$ Cohen and Levinthal (1990).

${ }^{16}$ Cournot's approach (1838) is one of the richest and gives basic elements of firms' analysis known today. He is the first author to put forward the continuum from "la concurrence indéfinie", or perfect competition, to monopolistic competition (oligopoly, duopoly, monopoly); the perfect competition being the situation where does exist a very large number of firms equally small (or, so to speak, having an equivalent economic atomistic weight) and were the potential action of each of them does not affect the total production volume supplied. Since Cournot's interest was to propose a coherent and formalized analysis, he took the firm size as an explanatory variable of making prices: in both situations (perfect $v s$. monopolistic competition) firm size plays a big role for opposite reasons (i.e., market $v s$. monopolistic price). By the way, to move from perfect competition to imperfect competition leads to a conceptual jump from price takers (agents) to price makers (actors). Walras is simply going to systematize perfect competition to feature a general equilibrium (followed by Marshall and his partial equilibrium approach) where it is said that firms, as agents (or representative agents), are price takers. Stressing the point on imperfect competition, Robinson and Chamberlin went back to the size asymmetry by focusing on market power. Moreover, firms being actors, size becomes a strategic variable... Here, we are only concerned by imperfect competition as well as strategic actors but not on a basis where firm size is a main, or even unique, strategic variable since it is an error of contemporary economics (i.e power is systematically correlated to firm size). Market power is one thing, Negotiation Power (based on competency level and difficulty to replace, Bouvier-Patron, 1994), is a much more relevant topic.
} 
-(b) The Knight-Coase (1937) debate which initiated the invention of the Economy of Organizations based on incomplete contracts on one hand and information asymmetries on the other (developed by Knight, 1921; Hayek, 1945; Akerlof, 1970) ${ }^{17}$.

-(c) Simon (1947), Ashby $(1952,1958)$ then March and Simon (1958) on the development of a modern theory on organizations and learning based on bounded rationality and complexity.

- (d) Penrose (1959) on the building up of the firm as a group of competencies in a long structuring and by taking into account evolution and change; this way of building abilities has partially been explored later by Teece et al. $(1980,1988)$.

- (e) Schelling $(1956,1960)$ for the analysis of social interactions and coordination integrating the crucial parameter of contextualization; and then, subsequently, Selten (1978) for his specific model of contextual and temporal strategic behavior based on reputation effects.

-(f) Burns and Stalker (1961) on the variety and the dynamic of organizational forms (in the context of innovation (Rosenberg, 1982; Kline and Rosenberg, 1986), which has given place to contemporary reformulation like that of Aoki $(1986,1988)$ ).

- (g) Ansoff (1965), for his famous strategic management approach (however by putting forward the organization/environment dichotomy which is a strong limitation).

-(h) Polanyi (1966) on the tacit nature of knowledge.

- (i) Georgescu-Roegen (1971) on the irrevocability of the processes of economic life.

-(j) Richardson (1972) announcing the obligation of taking into account the complementarity of activities (according to the dual concept: similar/complementary activity) to think about organization, firms and Industrial Organization; and Jacquemin (1985, 1988) for the representation of Industrial Organization on an evolutionary and cooperative basis.

- (k) Caves and Porter (1977) proposing the identification of strategic groups and of mobility barriers in the dynamical process of the creation of competitive advantages.

- (1) Weick $(1977,1979)$ on the interpretative building up of the action starting from freezing (rigidity) and the restriction, in theory, to a few among a set of possible perceptions.

- (m) Adoption processes of Katz and Shapiro (1985) combined with that of Farrell and Saloner (1986) on one hand and that of David (1985) and Arthur (1989) on the other.

The work of David (1985) and Arthur (1989), for the understanding of the diffusion and the selection of technological options where firms promote these options (especially by being promoters and/or themselves adopters), constitutes therefore, in the perspective of a changing universe and where the interactions between actors are increasing, a major explanatory mechanism of the current phenomenon of adoption and diffusion of technological options: path-dependency, increasing returns of adoption and small historical events (Arthur, 1989, p. 118). One can imagine that the small historical events make up grains of sand which have structuring cumulative effects leading to an irreversibility characterized by a path-dependent effect (which means affected by small historic events).

\footnotetext{
${ }^{17}$ The developments of information asymmetries are absolutely central in the contemporary analysis and it is interesting to see that they are the results of pioneer works (Akerlof, 1970) not highly considered at first or relatively forgotten since their publication (Knight, 1921).
} 
Before this decisive contribution, in a more restrictive manner, prevailed the now famous view point on the existence of a "Small world" (Milgram, 1967): the basic idea is that not all the possible connections are used to achieve a given objective. Whatever the size of a given space, only a few interactions within this space are required to reach this given objective ${ }^{18}$.

Having taken into consideration the importance this literature has today, we have to remember in detail how the question of diffusion and adoption is dealt with. The adoption of a standard depends on the adoption behavior by the other agents (the notion of network externalities, Katz and Shapiro, 1985; Farrell and Saloner, 1986) linked to positive effects both direct (according to the size of the community of adopters) and indirect (where the offer of compatible and complementary supplies - products and/or services are added and spread out the service brought to the adopters: which is a dimension of temporal dynamics). This explains the diffusion of an innovation as well as, and above all, the selection between several competitive technological options until technological "lock-in" (Arthur, 1989).

David (1985) however has shown that the chosen and adopted option is not systematically the best; Arthur (1989) has himself shown the importance of small historic events in the emergence of a "lock-in".

In the same way, Dalle (1995) explored a model where there was a choice between two technical options (according to the neighborhood of actors and Increasing Returns of Adoption) even if mutants paths exist.

Following the work of David and Arthur, Zimmermann and Steyer (1996, p. 70) underline that local relations can, with the contagious effect (sequential transitivity), lead to global effects (and "feed back effect" generally). There is, in general, an orientation towards a single standard amongst competing initial options. In the spatial complex structures (like those explored by the process of percolation) ${ }^{19}$, the dependence on initial conditions is crucial: which takes us back to the theory of chaos. However, a system need not be chaotic to be complex (Morel and Ramanujam, 1999, p. 280): complexity is mainly related to self-organization.

Zimmermann (2001, this issue) proposes, in a qualitative illustration and a given context, a precise examination of the layout of small historic events with the help of an example and concludes on the relevance of "Small Worlds" (Milgram, 1967) and of "Self Organized Critical" or "S.O.C" which is a fruitful concept strongly related to selforganization. Morel and Ramanujam (1999, pp. 281-282) show the interest of SOC, related to Simon's (1955) work on the $1 / \mathrm{f}$ law ${ }^{20}$, by the avalanche allegory: it is only a few additional grains which produce an avalanche and it is this quantity which it is

\footnotetext{
${ }^{18}$ The anecdote which is often quoted is that relative to the quite restrictive private network that a US citizen needs to send a letter to be received by the president of the USA.

19 The mimetism of competitors and diffusion, by percolation, allow the explanation of self-organization phenomena.

${ }^{20}$ Morel and Ramanujam (1999, p. 282): "To explain the ubiquity of the 1/f law, Simon (1955) demonstrated that $1 / \mathrm{f}$ distributions correspond to the stationary state of stochastic processes where the probability that an event occurs is proportional to the number of times it has occurred in the past".
} 
necessary to appreciate. Using simulations, it was shown that the frequency of avalanches is inversely proportional to their size (which follows a $1 / \mathrm{f}$ distribution): such a system is then called "Self Organized Critical" (or SOC). This SOC principle, or 1/f, is one of the principal characteristics of complex systems.

There were many efforts interpreting the work of Arthur but those about transcending are more exceptional. Auriol and Benaïm (2000) are studying in great detail the phenomena of adoption at individual level (decentralized economy) and its result on the whole economy with the help of the introduction of a variable, the tolerance to incompatibility: this modifies considerably the central role played by the phenomenon of path dependency and lock-in proposed by Arthur. Indeed, the aversion to incompatibility is a key variable used to explain the systematic emergence of a "lock-in" and induces a nonpredictable systematic process of adoption on a given standard (by the way, it possibly leads to dominated standards). The tolerance of incompatibility induces that the standardization (resulting from a "lock-in") is not systematic but the adoption process is highly predictable; furthermore, the neutrality to incompatibility systematically leads to the emergence of a standardization on the dominant standard. The interpretation of the implicit coordination underlying these results remains open even if the authors conclude that it is a kind of set of myopic actors leading to an unconscious maximizing behavior.

Still in a dynamic model of adoption, extending their analysis above in order to test its robustness, Auriol and Benaïm (2001, this issue) underline how much the economic literature on network externalities is silent on the question of coordination whereas the proposed directions of research thanks to evolutionary game theory is helpful. It turns out that the multiplicity of standards in competition $(n>2)$ does not allow convergence but an oscillation which corresponds to a failure of standardization, which can generate a major crisis of confidence for consumers (then a critical drop in demand). In the present case, there is no emergence of self-organinization.

This type of work belongs more to the modern acceptation of self-organization: that is to say, the emergence of a spontaneous order which is a very powerful one but only one of the possibilities.

\subsection{From chaos to self-organization: recent contributions of Complexity Sciences to firm and organization theories}

For an application of chaos to the theory of organizations, one can go back to Thiétart and Forgues (1995, p. 19) who highlight the contradiction of chaos as a visible result of randomness but which relies in fact on deterministic behaviors. According to Cosnard (1991, p. 73), chaos is explained by a dependency and a sensibility to initial conditions where the imprecision of initial conditions leads to the unpredictability of a system which becomes chaotic.

The characteristics of a chaotic system explain what is at work in the economy:

- nothing is ever the same;

- a lot of sensibility to the initial conditions since a small modification in the initial conditions, at the start, can generate later huge effects on a macroscopic level; 
- determinism, that basically governs the system (according to the existence of legal framework, structures and rules), gives nevertheless unpredictable results which are at the origin of branching off ${ }^{21}$.

It is quite clear that the theory of chaos cannot be scorned. Dooley and van de Ven (1999, p. 360-361) explain how the analysis of dynamical systems allows the study of chaos and noises. One finds five models of temporal patterns: the static model, the cyclic model (or periodic), the strange model (chaotic), the noises (pink, brown, black) and the random model (white).

Let's feature periodic, chaotic, noise and random models by the following proposals (Dooley and van de Ven, 1999, p. 361, p. 365-367):

- The difference between periodic and chaotic is that the periodic results from simple independent linear interactions whereas the chaotic results from interdependencies on a global level.

- The random model, white noise, results from multiple causes acting in an independent fashion from each other.

- When there are inter-dependencies between causes, different structures of noises can be extracted: like white noise, it is still about random movements but which goes, compared to the white noise, in the same direction (as is the case of brown and black noise) or in the reverse direction (as in the case of pink noise). The additional particularity of the pink noise is to favor low frequencies compared to other noises.

However, the most important thing here is not periodic, chaotic, noise and random models but complexity. Boisot and Child (1999, pp. 241-242), beside Simon, highlight the work of Kauffman $(1993,1995)$ as a major one for the development of complexity approaches. For Kauffman (Morel and Ramanujam, 1999, p. 280), two axes appear as crucial (a) the global analysis of network interactions; (b) local or spatial interactions.

(a) Kauffman (1993), in using the language of Boolean NK networks (borrowed from Wright in the thirties), is studying the relations between the nodes of the network according to the variable degree of the density of links.

$N$ represents the number of elements of the considered system. Each element has a fitness contribution depending on this element as well as $K$ other elements (among the $N$ ). $K$ represents the richness of the cross-coupling within the network. With $K=0$, there are no interactions. With $K=N-1$, we have the maximum possible interactions (where each node is affected by each of the others). It is about a general framework which is particularly useful for thinking about interactions within the economy in terms of self-organization.

(b) Kauffman's argument (1995), according to Anderson (1999, pp. 223-224), is that if a small change in behaviors (through a cascade effect) leads to too small a jump, the system cannot evolve much. This is why, on the contrary, in a universe of a chaotic type (see above), small local changes could more likely lead to varied and different peaks,

\footnotetext{
${ }^{21}$ The branching off is treated theoretically by Prigogine and Stengers (1979) throughout the "Dissipative Structures" (inspired, conceptually, from the theory of catastrophes: Thom, 1980).
} 
thus the system can make jumps allowing evolutions but do not allow them to remain on these peaks (furthermore it does not prevent being in areas of no interest and those are very weak peaks). Because the peaks tend to be located near each other, it is possible to join a continuous satisfying learning path and, at the same time, the system can reach higher summits than the evolution would likely give by learning. This is where the importance of the landscape and its topology comes from (concerning the organizations: Boisot and Child (1999, p. 242) as well as Poncet (2001, in this issue)).

In this situation, Kauffman (Morel and Ramanujam, 1999, p. 283) focuses on interactions of sites where the state of a site is affected by the state of its neighbor(s). Through time, the different neighboring sites lead, spontaneously, to self-organization; the number of interactions intervene as a crucial parameter, Weisbuch $(1991)^{22}$. Here, self-organization is related to systems composed of dynamic interactions between neighboring sites (Morel and Ramanujam, 1999, p. 283).

Both $(a, b)$ lead to an understanding in terms of self-organization. According to Morel and Ramanujam (1999, p. 288), let's have a look at the role of self-organization for firms and organizations:

- great numbers are relevant in experimental sciences to explain self-organization but what is a great number is problematic in social sciences: if, for example, in the case of the Internet (with millions of users who can interact), we are close to the numbers of experimental sciences, within organizations several hundreds of individuals mean a great number;

- at the level of organizations, the fact that each individual plays several roles appears to be primordial and taking all individuals of a given organization leads to a great complexity and, possibly, to the existence of self-organization (that does not then need a great number).

Self-organization is the capacity of a system to develop itself, to acquire new competencies and/or to modify, from the inside, its working.

As Paulré (1997) explains, two conceptions of self-organization exist:

- "A system is self-organising if it modifies its initial structure according to its experience and its environment" $\Rightarrow$ (pioneer approach) Interaction;

- "A capacity to make a global structure from local processes which is not imposed, nor deliberately developed by basic elements" $\Rightarrow$ (present approach) Emergence.

From these two conceptions, circular interaction with the environment or emergence, the first notion is mainly associated with learning.

It is why it is preferable to refer to the definition of the following synthesis: one calls self-organization the capacity that a system has to produce on its own (and in a manner that is not necessarily voluntary or conscious), a structure, an organization, a new behavior and/or the rules of working of the system.

\footnotetext{
${ }^{22}$ In other respects one can refer back to Weisbuch (1991) for a more systematic presentation of different models taking into account non-linear interactions: in particular, neural networks. On this last aspect, one can also refer to a special issue of the European Journal of Economic and Social Systems (2000).
} 
The theory of self-organization has to be promoted as an explanatory principle. In economics and management sciences, this theory plays and is going to play an increasingly large role: particularly, within and between organizations. The organization then depends on its learning, as well as internal and external evolutions and outside opportunities. Therefore, we need to understand what kind of relationship does exist between organization and change.

\section{Organizations and change: how to learn, build and renew}

At first glance, the fairest intuitive representation of an organization, at this point in time, is that of a living cell which uses inputs to grow and then delivers to other cells the good (or goods) that it has developed. Putting forward organizations ( $c f$. Sect. 3.1) as living entities confronting uncertainty is required before understanding ( $c f$. Sect. 3.2) the way they build themselves as well as (cf. Sect. 3.3) how they learn and renew themselves.

\subsection{Living organizations faced with radical uncertainty}

Form the start, it appears absurd to oppose the organization to an external environment as the organization lives with and thanks to this exteriority. This vision of things comes out more and more with the concept of co-evolution (Organization Science, 1999b). To give an accurate meaning to the concept of co-evolution, one can refer back to Paulré (1997): the agents or set of agents co-evolve in the sense where they not only structure and transform, collectively and individually, their common environment but, in addition, because of the competition, each agent participates to the structuring of the others' environment.

This consideration is not recent, as Porter, after his famous but questionable work of 1980 ("competitive advantage") self-criticized himself in his no less famous ("competitive positioning") of 1985 where from initial simple competitive positioning, he went on to articulation of the internal/external link and the question of the value chain (Porter, 1985). In fact, the success of the firm depends indirectly on its competitive positioning and is founded first of all on mobilizing internal "Resources" (Wernerfelt, 1984) to obtain this. The analysis of resources however turns out to be too static and furthermore, less relevant than that in terms of "capacities" (Penrose, 1959) leading quite directly to a concept of competencies. The risk is to be locked in a debate on the relevant economic horizon in reducing it to a simple short or long term quarrel (limiting in this way the contribution of Penrose (1959) to an opposition of paradigm short term/long term).

Moreover, in a dynamic framework where the multiplicity of interactions prevail, the double dimension which is relevant is that of internal capacities not only articulated into a single firm but also between firms (Richardson, 1972).

To go back to Simon's allegory (1991), the world which would be drawn by placing oneself like a Martian observing human society would be that of a collection of organizations linked to each other by quite weak, strictly economic flows.

In the framework of market activities, the organization is called a "firm". The firm can be taken as an organization, like any other organization, with the particularity of buying inputs and selling outputs by making a positive differential between that which is sold by it and that which is bought by it. This restriction induces a specific working, called 
"management" internally and "making business" externally. Which are both particular to each firm and the result of a specific history: these two contextual elements state what is called "business culture". A business culture (for an analytical reference, Kreps (1990) as well as Crémer (1990 and 1993)) is the basis on which is built business management, in the broader sense of the term, at a given time. Even more generally, the qualitative arguments of confidence or atmosphere, internally as well as in the framework of business relationships, play a predominant role (respectively, on one hand, Breton and Wintrobe (1982) and, on the other, Hakansson (1982, 1988, 1989).

It is therefore essential to underline that business management is not shielded from fashion (fashion seems to be taken for granted, at a given time, by managers of the majority of firms) and also uses norms (which impose themselves, at a given time, and in a more or less durable way, depending on the longevity of the convention). The norms can come from the State (as in the case of the obligation to provide bookkeeping documents as well as, and above all, social legislation) or else from the semi-public sector, even the private sector as in the case of adhesion to an ethical or technical charter.

In fact, fundamentally, it would be erroneous to consider the trajectory of firms as univocal and straight (due to the importance of the past, for example) because (a) the constant interaction with the environment, (b) the necessity to absorb shocks or hazards (as well as dealing with environmental changes) and, finally, (c) the need to anticipate future events ${ }^{23}$ ( $a, b, c$ being factors of uncertainty) induce a "fine tuning in piloting" more or less skilful (depending on the know-how and skills control of the pilots) and more or less brutal (depending on the harshness of the shock and/or of the scale of the correction to operate or of the modification to bring).

This uncertainty is radical (Knight, 1921): it concerns the difficulty, in a market economy to estimate the right decisions to take in anticipating future needs and taking into account the rivals; the market being the natural vector of uncertainty in the economic sphere.

In an economy full of radical uncertainty, an organization is a building like a stabilized space where uncertainty has, in this case, been reduced in a satisfactory way to allow the making of values (reduction does not mean elimination) ${ }^{24}$.

Making models seems at first very difficult in that field since the proposal of Knight (1921) to not have any other choice but to consider an economic life surrounded by radical uncertainty.

Within such a context of uncertainty, one must follow Keynes (1936) who states that the expectations are only possible by taking the conventions into account (a convention existing at $t_{0}$ is directing what the future would be without determining it because of

\footnotetext{
${ }^{23}$ A crucial point is the ability to anticipate future events in a context of singular situations, each situation being unique: this features decision-making in radical uncertainty, which is the core of Knight's (1921) work (for an analysis of this author, Bouvier-Patron, 1996a). However, besides the fact that the future is unknown (then, objectively non-probable), Knight's proposal goes along very well with the work of Shackle (1979).

${ }^{24}$ For Knight, the principal method of uncertainty reduction, or Grouping, consists of socializing uncertainty. By extrapolating, this idea of Grouping can be analyzed as a structuring of the environment by common putting up and common procedures to obtain an assurance on the means used when it will be necessary to carry out the business decision on an uncertain achievement. There is no reason, in fact, to limit this assertion to the internal organization of the firm.
} 
radical uncertainty). Expectations depend, at $t_{0}$, on the idea that one has about the future: this highlights the importance of the question of the building up of expectations because the actors can only think, at a given time $\left(t_{0}\right)$, about the future in conjunction with the idea that they have formed $\left(a t t_{0}\right)$ within a given convention. It remains to be seen up to what point it is about self-fulfilment prophecies, how achievements arise and, finally, to which extent radical uncertainty is involved and possibly destroyed ideas, expectations or conventions (Bouvier-Patron, 1992). In such a context, the reviewing anticipations then make sense and do mean adaptive expectations, as has already been highlighted by Simon (1958) and taken up again by Le Bas (2001, this issue).

In the total absence of objective information on what the future will be, the deciders cannot however commit the whole organization in the long run according to Keynes's proposal (1921) on the equiprobability of situations (supposing that these eventualities can be enumerated and understandable by the deciders; this hypothesis remains however crucial in a formal framework respectful of what radical uncertainty is): that is to say, the maximum point of uncertainty. The deciders always have a certain idea of what they want to do and of what can happen (without necessarily using a subjective distribution of probabilities). It is thus the capacity to build a representation which is fundamental.

Uncertainty can be perceived as a surprise (Shackle, 1961) according to the gap between available knowledge and that necessary to move towards the achievement of what had been imagined. Learning occupies a large place in this progression, to be followed or discovered. The base of knowledge is solid if the available range of possible replies is sufficient and/or satisfactory. Which means that there is no rigidity but a possible adaptability and therefore a flexible representation system... This does not take into account possible limits related to bounded rationality of decision makers when they are out of a given routine... However, "brain storming" and/or other procedures implemented within the working of organizations can allow the avoidance of, from the bottom (decentralization) and at an acceptable cost, too large a bias without, however, guaranteeing that a right decision will be taken thanks to a good representation (that is to say, a satisfactory representation or "satisficing").

The friction between impulsion of a change (no matter who initiates it for the moment) and the present routine is the heart of the process explained here. This is what motivates Weick (1979) to look for a stable point: the arbitration, which is to be found between flexibility and stability.

The impediments to change, or resistances, aim to keep the organizational working as it is whereas the impulsion(s) of change aim at reforming the organization or its rules. Naturally, the source which initiates the change has a large importance in understanding what is at stake:

- Internal origin (if internal, who and where in the hierarchy?);

- External origin (if external, is it indirectly by taking into account new parameters as an environmental restriction or, directly such as in the merger ${ }^{25}$ cases?).

\footnotetext{
${ }^{25}$ In the case of a merger, the positive and voluntary choice of such an operation of equal parts differs from that lead by constraint from a dominant firm on the other (case of a merger with a leader, case of absorption of a third, case of buying out a weak firm by a more powerful one).
} 
The management style must favor change and support it without necessarily initializing it. The management style (Doz, 1994, p. 98) must therefore support a process of internal knowledge aggregation without leading to a standardization and elimination of grey zones necessary for creation, which is only possible by escaping from a severe control (Thiétart and Forgues, 1995, p. 22): the necessary broadening of knowledge implies remaining up to date (in order to satisfy current needs) by enriching and combining knowledge (Doz, 1994, p. 99) to respond to new needs.

In this way, for example, thinking with more or less controllable causalities, the question of "power", closely linked to the nature of the source after identification, is going to be an essential key in the understanding of the management process and/or the decision making, facing uncertainty and change (... as well as the resistance to change).

Simon (1947) then March and Simon (1958) (having been taken up and popularized by Crozier and Friedberg, 1977 as well as Lemoigne, 1990) and, in their own way Cyert and March (1963) ${ }^{26}$, show that the working of the organization is based on the conflict of interests. Thanks to strategies that the actors will implement, these will try to make their own objectives accepted or will position themselves so that their interests will be preserved in the best way. The global process, however, tries to make everyone internalize the organization's objective and this is only possible where the proposed incentive is satisfactory (being involved is then always preferable).

To focus exclusively on internal power would be equivalent masking the question of the structure of the organization which, according to its flexibility or its rigidity, will not respond to a stimulus in the same way (internally or externally; of usual management or of managing the novelty or change). The structure of the organization is based on rules which govern its working.

The rules of working of a given organization are the result of a story as well as a permanent updating. The weight of history can be a determining factor, that can sometimes condition the nature of the power which is in place. At the same time, the new external conditions, which are not necessarily foreseeable, can bring about opportunities for change as radical as they are unexpected and healthy or fatal for a firm or an entire sector.

As an organization's backbone, all the rules mentioned appear to have a more or less large plasticity.

The interaction between history, structure, culture, power and evolution of the organization as well as the environment seems to be essential to explain the adaptation or the "resistance to change" or freezing: whether this is linked to an innovation (put into place internally) or that this results, externally, for example, from a desired merger (with an other) or forced merger (coming from another's will).

In fact, after having isolated the source (which initiates) "change", one must also be interested in the consequences of this impulsion in terms of interaction in, on and around

\footnotetext{
${ }^{26}$ It is this question, throughout the building up of coalitions (notably the majority coalition) at the heart of the organization which will be dealt with by Cyert and March (1963) but where the analysis of change is singularly absent. However, the analysis of the power at stake is determining.
} 
the organization. Thus, there is a triple fundamental level (Bouvier-Patron, 1999) as well as a fourth supplementary level:

- Intra-organizational (individual level);

- Organizational (inter-individual level);

- Inter-organizational (inter-firms level): (a) buyer(s)-supplier(s) relationships with Richardson (1972), Hakansson (1982), Farrell and Scotchmer (1988), Farrell and Gallini (1988) on one hand; (b) alliances with Dussauge et al. (1988) and Garette (1989), mergers and take-over with Chandler (1977) on the other hand);

- Interactions with the larger environment (public policies on one hand; links with final consumers on the other hand).

Also, the principles of communication which define the rules to coordinate individuals or organizations are to be promoted because rules (or more precisely the prevailing systems of rules which meet other systems of rules or new systems of rules) characterize the friction and reveal the nature and the particularity of resistance to change.

Contrary to the strategic planning of the sixties where strategic behaviors were programmed, Ansoff's strategic management (1965) aimed to make organizations awake in order to anticipate and control, more or less well and, at the same time, allowed them to react to (to face) disruptions and an uncertain context ${ }^{27}$.

Governing towards uncertainty invariably leads to questioning with regards to what prevails at a given time within a given trajectory and also available capacities which will give abilities to compete as well as to capture outside opportunities (Cohen and Levinthal, 1990). This is a good way to consider the question of co-evolution.

The important question is, at the same time, the co-existence of several organizational forms, or even the set of (all) different forms. If all of these forms do exist at the same time, will a major trend appear? Such is the careful invitation proposed by Desreumaux (1996) as well as, at the same time, urging us to be careful about the effective emergence of a post-bureaucratic model.

\subsection{Building up within and between organizations}

The variety of organizational forms within the concrete industrial organization has a certain importance to the extent where the coexistence of several types of organizational forms, at the same time, gives, to the whole economy but also to everyone (learning by imitating neighborhood), the ability to adapt oneself and reply to a large variety and variability of environments (thus, co-existence on a synchronic axis and co-evolution on a diachronic axis do exist)... A major phenomenon allowing these forms is the decentralization of information in a more or less explicit framework (Radner, 1992) ${ }^{28}$. Thanks to Burns and Stalker (1961), we shall try to restore this diversity.

\footnotetext{
${ }^{27}$ Note that in Ansoff (1965), like with others, the environment is analyzed more like an exteriority made up of threats or opportunities than as an analysis of interacting competitors' behaviors. And it is not by chance if the strategic interaction has become later at the heart of many works.

${ }^{28}$ Radner (1992) puts forward computer knowledge on networks architecture in order to show the importance of decentralization on the processing of information to reduce the response time of the organization.
} 
From both a logical (causality) as well as contextual (variety of situations) point of view, it should not be possible to lock oneself in too deterministic a reasoning:

- Indeed, to say that it is the environment which gives the organizational form and which dictates the evolution of the organization seems to be a determinism which is not acceptable except by denying all that has been said above. However, an organizational approach of a pure contingency type (where the considered environment imposes which is the adequate organizational form) is similar to the evolutionary approach proposed by Nelson and Winter (1982) where the environment acts like a selection mechanism towards organizations.

- On the contrary, the reverse determinism advocated by Chandler (1977), a sort of "dictatorship" of the internal power and the internal growth promoting big vertical integrated firms, is as excessive.

The basic model proposed by Poncet (2001, this issue), based on the synthesis formulated by Mintzberg (1979), is very helpful for the reasoning without constituting the claim of a given theoretical option (the only one provided by Poncet is done in terms of the theory of catastrophes: Thom, 1980). This model is built ${ }^{29}$ by the interaction between two units:

(1) Structure (parameters) - (2) Environment (variables).

Through this model, the classical opposite positions can be identified:

- Chandler's approach of "Organizational Push coming from internal management decisions" (determinism): (1) $\rightarrow(2)$;

- Pure contingency approach ${ }^{30}$ (determinism): (2) $\rightarrow$ (1).

Poncet's model (2001, this issue) is related to other works (Boisot and Child, 1999; Kimberly and Bouchikhi, 1995; Meyer, 1995) and uses conceptual tools proposed by Weber to explore bureaucratic systems. Is Weber's "ideal type" a tool or a norm? In the first instance, the affirmation according to which "moving away from the ideal type is no longer efficient" is an argument which locks the analysis on the comparative statics. On the contrary, in the proposed model, efficiency is not measured with regards to the ideal type but to the virtual form ${ }^{31}$. This leads to the possibility of transitory forms. One must put forward the fact that there are transitory inefficiencies between two ideals and that firms are, in real life, in movement between two but never on an ideal type. It is about highlighting that there are evolutions of firms. What is at stake is to look at erasing the comparative statics approach to move to a dynamic one.

At the same time, the structures evolve and are always between two ideals. Which creates a transitory inefficiency: the more firms act, the more they place themselves between two ideals. Firms evolve in reality and are featured here by a virtual model of the firm and its evolution, the evolution of the virtual model as having been conceived as the consequence of the evolution of a contingency factor.

\footnotetext{
${ }^{29}$ Limits of this model can be summarized thanks to a question: how to take into account the co-linearity between the variables and the co-linearity between the parameters?

${ }^{30}$ Which, by the way, could be related to Nelson and Winter (1982) where the environment is the selection mechanism.

${ }^{31}$ Notice that for Lawrence and Lorsch (1967), there isn't an ideal organization in the sense that all organizations must be flexible to environmental demands.
} 
Poncet's contribution helps to come back to one of the implicit starting points linked to Management Sciences that we would like to leave behind. The theories of contingency are very widespread because it helps mainly to take into account and understand the diversity of organizational forms. In the proposed model, certain simplifications are proposed and reinforce, in the first instance, a deterministic analysis: it is only about giving a pedagogical framework for thought. By the way, this theory should not be neglected because what is a "new" organizational form is still unclear: this is why, as we have already said, Desreumaux (1996) asks us to be careful by thinking in terms of a postbureaucratic model (thus leaving behind contingency approaches of the organization).

However, one needs another way of thinking. At this stage, is it then better to speak about reciprocal adjustment rather than co-evolution? One can see here the important role of internal structuring to build up adaptation capacities (Weick, 1977, 1979). Moreover, Weick (1979) highlighted very early on the importance of the environment for the organization and too the permanent interactions between the organization and the environment, on one hand, or the process by which the managers select (and eliminate), appropriate and impose few selected elements amongst many others possible (process of "enactment") on the other hand. It appears that the efficiency of the organizational form results more from the appropriateness between the rules of working (in the sense defined above) of the organization implemented on one hand and the environment to the other rather than the automatic correspondence between an organizational form and an environment.

No matter how, it is the reciprocal interaction organization-environment which appears determining as well as the dimension of co-evolution.

A comparative perspective is often interesting: Burns and Stalker (1961) distinguish the mechanicist organizations of hierarchical type ${ }^{32}$ and the organicist organizations of matrix type (Mintzberg, 1979):

- The coordination is pyramidal (hierarchical), in the first case, so a strictly vertical type, whereas it is rather horizontal in the second case;

- The circulation of information is vertical in the first case whereas it is horizontal in the second case;

- The structure of decision is centralized in the first case whereas it is decentralized in the second case;

- If the environment is stable (without any shock or any innovation supposed possibly to put into question the present behavioral routines and rules), thus the mechanicist model is suitable; on the contrary, when the environment rapidly changes, the organicist model will be more effective.

By following Burns and Stalker's perspective, one can suggest (Bouvier-Patron, 1994) three states of the environment: E1 (stable), E2 (intermediate) and E3 (unstable), in

\footnotetext{
${ }^{32}$ It does exist two main (complementary) traditions: Taylor with a double separation -conception/execution- and -centralization of decisions/breakdown of work into a segmentation of insulated tasks- on one hand; Chandler (1977) organizational forms being (a) functional, then (b) divisional as well as (c) multidivisional on the other.
} 
accordance with Aoki's hypothesis (1991, p. 21). These three states of the environment correspond to three levels of information affecting the organization's strategic level: $i_{1}$ (no new information), $i_{2}$ (new information demanding an adaptation of the initial level), $i_{3}$ (new information demanding a revision). The idea of making the flexibility of the organization (A or J) conditional on a state of the environment was the object of a model proposed by Itoh (1987): the model A (particularly well adapted to the state $\mathrm{E}_{1}$ ) is opposed to the model $\mathrm{J}$ (particularly well adapted to the state $\mathrm{E}_{2}$ ). In fact, the organization having the most rigid skeleton (organization A) will be, because of its autonomy in regards to the environment, quite well adapted to it if the state of this environment is a polar one: that is, stable $\left(\mathrm{E}_{1}\right)$ or unstable $\left(\mathrm{E}_{3}\right)$. On the other hand, in the intermediate situations $\left(E_{2}\right)$ where a continual stream of new information demands a lot of adjustments, it is the most flexible organization (J organization) which will be the most adapted. The reason is attributed to different types of variables which feature the models of coordination A and J: that which will prevail is the harmonization between the active variables of a given model with regards to the type of environment.

If one follows Aoki $(1986,1988)$ on the opposition of the forms $\mathrm{A} / \mathrm{J}$, the analysis of comparative circulation of information leads to the following statement: a lack of reactivity of the model A built from a centralized vertical system of decision which can only react too late or with a hitch. This is an example of prejudicial linearity to the effective working of a concrete complex system.

Now, in the concrete economy, the hierarchical pyramidal type seems to predominate, still today, as a type of coordination within as well as between organizations.

It is however more likely, on the practical level, that the two models (centralized vertical, decentralized horizontal) coexist more or less within the same organization and equally, in terms of repartition, in the population of organizations. The goal of managers, the true working of the organizations and environment variability (alternating situations, for a more or less long period, where the environment is stable and situations where the environment is changing) lead implementing this co-existence. More likely, in reality, one finds hybrids between these two models. These hybrid forms result from blending, with, however, a clear domination of the mechanicist model (amongst the population of firms and for any single firm).

However, in periods where information is from the $i_{2}$ type, it seems important to take into consideration a hidden variable, that is to say the inter-firms dimension. Which leads to explaining the efficiency of the J model. Vertical integration practiced by A firms is dropped by J firms which rely on a long term contractual policy with suppliers.

These ideas were taken up and synthesized, on an analytical level, by Aoki (1986, 1988, 1990, 1991) but to achieve his work, Aoki was particularly indebted to Crémer (1980) and Itoh (1987). Crémer (1990) insists above all on the necessity of showing that the circulation of information, in the considered organization, is first of all a collective process, that this process is not necessarily hierarchical (as soon as the existence of lateral relations between the actors within the same organization is recognized) and that the unification of behaviors is based on the taking into consideration of rules, or even of a common culture which is more specific ("coding") and not necessarily formalized, which is fundamental for the renewal of competencies. 
To summarize, the hierarchical form is not questioned in the sense where hierarchy is required in an organization. The hierarchical model A or J, chosen or inherited, and the type of working (through worded and enacted rules in the framework of the business culture) are not neutral and have an effect on the way of facing uncertainty, favouring organizational learning and the governing of change.

Finally, one will propose the following extended definition of the organization: the organization is a group of rules, imposed or negotiated, to achieve objectives in mobilizing and in coordinating, in a structured way, a group of human actors (who do not necessarily have identical interests ${ }^{33}$ ) as well as material and immaterial resources even when the organizational frontier is open and, the greater the opening, the more the interaction with other organizations becomes a determining factor in anticipating in order to adapt and/or act on the environment.

The minimal implication of this definition is that the organization is a collective body as we have already said and that the significant space is not only the intra-organization but the inter-organization. The double dichotomy firm/environment, organization/market then loses all its meaning.

To understand the question of managing change, analysis of the organizational structure and its opening are required in the first place. Indeed, it is thanks to the structure that one can find out formal and informal rules of working and coordinating individuals within the organization and between organizations. From that, a basic typology of organizations is required. The typology which we suggest (comparable to the one of Miles and Snow (1978 and then 1992) on networks, discussed in a detailed way by Desreumaux, 1996) explains possible Internal forms $(H P, H D, M)$ in relationship with an External one: - "HP": Internal organization with a Pyramid-like Hierarchy (simple Unitary or Multidivisional) with descending information (Chandler, 1977; Williamson, 1985);

- "HD": Hierarchical internal organization with a circulation of information and Decentralized decision (Aoki, 1986);

- "M": Internal organization supporting a density of (formal and informal as well as centralized and lateral) exchanges between individuals, duties or competencies (Matrix type: complex network strongly connected) that we find back among other forms in Mintzberg's synthesis (1979);

- "E": External organization of inter-organizational star type with decentralization of the information and decisions processing: between linked organizations coordinated thanks to a vertical hierarchy (Aoki, 1986) or to an horizontal hierarchy ${ }^{34}$ (Richardson,

\footnotetext{
${ }^{33}$ It is this question, throughout the building up of coalitions (majority coalitions) in the heart of the organization, which is going to be dealt with by Cyert and March (1963) but where the analysis of change is singularly absent.

${ }^{34}$ Here, in the vertical relationship of complementarity activities (Richardson, 1972), the buyer-supplier one mainly, the domination of one party over the other is not retained while cooperation imposes itself (Thiétart and Koenig, 1987). The hierarchical nature of the relation is then flat or horizontal (as opposed to the vertical one as in Aoki's J network). However, this situation has to be balanced according to the Negotiating Power (Asanuma, 1989; Bouvier-Patron, 1994) of each of the suppliers. Negotiating Power is a different question of that of Negotiation (very important for Management Sciences, Rojot, 1994; and highlighted, in the thirties, in Economics by Zeuthen).
} 
1972; Thorelli, 1986). More complex forms can be found depending the number of actors involved and the connexity degree of links between them as well as type(s) of hierarchy involved each time.

In economics, we tried to develop the question of networks (Bouvier-Patron, 1992, 1993, $1994,1995,1996 \mathrm{~b}, 1998 \mathrm{~b}, 1999)$ in an independent way and parallel to other authors linked to the field of Purchasing Marketing (a field of management sciences) whose emblematic figure is Hakansson $(1982,1988,1989)$ and also, in a less extent, Thorelli (1986). Interfirm cooperations and networks are now a very important vector of creating and managing products innovations.

\subsection{Learning and the renewal of competencies}

Governing change depends on two main factors: (3.3.1) learning and (3.3.2) the renewal of competencies.

\subsubsection{Learning}

It must be highlighted that to focus on reactivity is not satisfactory as it leads to a defensive attitude. On the contrary what is at stake consists of, if possible or to a possible extent, getting used to anticipating (in other words, to decide in the face of uncertainty: Knight, 1921 and Keynes, 1936).

The questioning ${ }^{35}$ of rules which prevent the desired evolution leads to a move that could clash with the interests of those which are based on prevailing routines.

In such a conflicting approach, one can only speak about organizational learning ${ }^{36}$ in the wider sense of the term and where the logic of confrontation is in fact the cause of an evolution (no matter which), evolution which, taken as the transitory result between two different states, will allow in the aggregate and will roughly qualify a learning situation.

The organizational learning which Argyris and Schön (1978) spoke about was largely inspired by the ideas of Ashby $(1952,1958)^{37}$. Ashby introduced the distinction adaptation/learning where learning was the stronger concept. Consequently, he highlighted the importance of the "double feed back" effect (or "double loop"): the system firstly deals with a disruption as minor ("single loop") then, if this leads to a failure, it deals with this as major to generate a modification of the action plan ("double loop"). Two forms of "feed back" exist then according to Ashby (1952):

- single loop (do not repeat the error);

- double loop (modify the action level).

Combining both effects at a superior level (or "triple loop" by extrapolating Argyris and Schön, 1978) can be thought of in terms of learning how to learn as a generic competence.

\footnotetext{
${ }^{35}$ Who by? In the name of what interests? This is what needs to be determined, case by case, in a spatial and temporal framework.

${ }^{36}$ According to Crozier and Frieberg (1977), organizational learning is defined in the following way: discovery and development, by trials and errors, of new behaviors which form a system.

${ }^{37}$ For a presentation of this author, Paulré (1993).
} 
The boundary of the approach is found in the selection procedure by trial and error thanks to the answers taken in a preliminary tank by an automatic procedure (and which is not of a constructionist type, Paulré, 1993).

The organizational learning should deal with a controlled process (the change being generated internally or initiated externally by positive capture or by undergone importation) inherent to the rules of working set up in a specific organization and thus providing a suitable governance facing a given uncertainty (for all sources of possible uncertainty). In other words, the art of governing towards uncertainty would not normally be related to luck but should result from procedures learnt (and, logically, regularly updated) by the set of actors of a given organization. In fact, the implicit question is to determine if these are the behavioral norms and/or the framework of reference which change? Evidently, the rules of organization should generate the behavioral norms flexible enough to accept, think and integrate change even when the reference framework (where the change is generated) is always bigger, difficult to control, without known origins and is a permanent evolving motor.

One finds here a fundamental law grounded by Ashby (1958): the law of requisite variety for the system. Which gives, according to Rosnay (1975, p. 130), another way of thinking complexity of organization: the more complex a system is, the more the control system of this system should, itself, be complex; it is particularly important in order to give a "response" to the multiple disruptions which come from the environment.

It is imperative to keep to the internal variety of an organization in interaction with an infinitely complex environment as one can only regulate a system with the help of a control system which is as complex.

Naturally, the force of conviction of the members of an organization, the importance of this organization in the superior reference system (economy, culture, society), the outside interest of the proposed services (products and/or services) of this organization, the common culture of the members (Kreps, 1990; Crémer, 1990 and 1993) and the aptitude (allowed or impeded by the rules of working) to anticipate (and thus to govern towards uncertainty) make up key parameters to operate a change as well as, as much as possible, to adapt the environment to the needs of the organization (when the change comes internally by a relevant building up of expectations). In this case, even if it is not always possible, one must not neglect the potential "macro-economic" impact (bringing about an irreversibility, $c f$. networks' externalities) initiated at the "micro-economic" level. However, the question remains the same: how to generate such irreversibility?

The willingness to initiate such an irreversibility can succeed in the framework of an economic challenge but this is not compulsory and rather than deluding oneself or creating pathogenic attitudes, for and inside the concerned organization, counting on the force of will, it is always better to have a look at rules allowing the working of an organization and to assess if these rules provide a possible suitably adaptable governance towards uncertainty.

Essentially, the problem is not to foresee that which cannot be foreseen but to work on the implementation of internal rules (that is to say, principles of working of the organization) then, between organizations linked by common projects, allowing the adaptation of behaviors and organizations in a positive way for these organizations. 
One can therefore have a better understanding of the work of the psychologists of the organizations (like that of Weick (1979) which shows the importance of representations and the way in which organizations manage to interpret and/or define the constraints (but not always to respect them); taking the problem by its difficulties (or obstacles) initiated by the organization itself (or its constituent elements) to reach the aims that it has fixed itself (or the strategies that it develops, by catching the opportunities opened by the environment which is more or less open and more or less changing). Thus, the firm can generate its own brakes or impediments. This is a serious handicap in all situations calling for a reform of identity: from which come the impossible solving and overtaking of a given problem or else the impossible management of an essential evolution (sometimes imposed). The difficulty of questioning oneself becomes the difficulty of leaving a bit one's past (and so, a bit, oneself for each member of the considered organization).

The positive learning ${ }^{38}$ of change by the rules of working implemented within the organization should be a major factor of success.

The internal decision making of the organization should be shaped by this concern.

\subsubsection{The renewal of competencies}

As we understand it, there is a real dilemma of the organization in its research of an internal organizational balance ${ }^{39}$ always hard and fragile to obtain (as it is to preserve it): too much uniformity prevents evolution and too much variety prevents coherent development (Doz, 1994, p. 94).

This is particularly crucial in the matter of innovation or organizational learning in general: there is a necessity to make explicit what is tacit in order to develop the key competencies while, at the same time, contradictorily, it is necessary to be able to preserve the informal and the variety which are the only ones allowing change.

The development of a unique nucleus is possible, which grows bigger, generates inertia and can prevent access to openings or to creation. Naturally, a trajectory still exists since there is no strategy of "zero base": what the organization can do tomorrow depends on, to a large extent, what it can do today. A certain determinism can exist since what the organization knows how to do today results from that which it learnt yesterday (initial trajectory). Thus, the key competencies are a competitive advantage to build and develop as well as a potential source of inertia preventing the finding of responses to new situations. Key competencies increase of fitness to cope with similar niches but make this aptitude incapable of facing change.

It is necessary to know how to cultivate existing primary competencies in the core business as well as, at the same time, secondary competencies: Weick (1977) highlights, as we have already said, the importance of these secondary activities (away from the core) to respond to complexity and to change. These secondary competencies, linked to the first, allow the study of new combinations and avoid falling into a

\footnotetext{
${ }^{38}$ Flexible and distant aptitude to find out the effective problem and bounce on time.

${ }^{39}$ Internal equilibrium linked to the stability/dynamic balance which Weick (1979) speaks about.
} 
long-term routine prejudicial for the firm: this is where the absolute necessity of mobility ${ }^{40}$ comes from.

This is why the central question (Doz, 1994, p. 96) is that of renewal of competencies which is required itself in a self-organization perspective.

For this, it is necessary to conciliate two things which are opposed:

- The precise codification of competencies facilitate their internal diffusion, the deepening and the performance;

- The key competencies should be exploited in continuity but with a widening basis so that the competitive advantage is not a source of inertia.

Henderson and Clark (1990) show the importance, for the firm, of its link with the market and the necessity of the recombining process of technologies and competencies on the synchronic level (between those which already exist) and diachronic (between old and new): which leads these authors to talk about the concept of Architectural Innovation. Putting forward incremental type innovations (Rosenberg, 1982; Kline and Rosenberg, 1986) in comparison with those which are radical seems to be a confirmed fact: this is the key to the significant success of Japanese firms before western firms responded to the challenge in the eighties.

Thiétart and Forgues (1995, p. 23) also underline the necessity of experimenting on new solutions (and so, the possibility left by the management to experiment on new solutions). These authors demonstrate so well that linear planning (rather than what is blurred, intuition, free initiative) can only lead to a catastrophe: what is important is the preservation of truth, of non-linearity, of the density of exchanges and so the internal interactions as well as those of internal/external type.

Doz (1994, p. 97) as much as Thiétart and Forgues (1995, p. 22) explains the importance of leaving a certain flexibility and a woolliness inside internal procedures because of exhaustive specifications and strict adhesion to procedures stifle learning. The style of management (Doz, 1994, p. 98) plays an eminent role in promoting this necessary flexibility: the style of management must support an aggregation process without any kind of a hyper-specialization. The broadening (of competencies) also requires precision (to satisfy better current needs) by permanently enriching or combining or recombining (Doz, 1994, p. 99), to be able to confront new needs.

It is precisely from this dilemma which the communities of practice ${ }^{41}$ (Brown and Duguid, 1998; Wenger and Snyder, 2000) are able to free themselves. The literature on the communities of practice describes the working of these communities who have a passion for new technologies.

\footnotetext{
${ }^{40}$ Such a mobility is obvious on a given market: Caves and Porter (1977), and then Porter (1979), show the existence of strategic groups and mobility of firms as well as barriers to mobility in the dynamical process of the making of competitive advantages.

${ }^{41}$ The communities of practice is defined as a group of people who are involved in a common approach, an approach linked to the practice of an activity, and who communicate regularly with each other about this activity. Self organization is a key characteristic of such communities.
} 
One knows that organization, whatever its form, is no longer the only possible vector of valorization of knowledge. Learning is proven to be at the heart of this energy and allows one, at the same time, to build up competencies and practices but also to develop them, modify them and, above all, to get new ones internally by creation and/or externally by acquiring them or by gathering outside information. This is where the main principle of self-organization is to understand the creation of a new order which emerges.

However, on to the point of view of a managing conception to implement (much more important than any not efficient organizational willingness), what is important is to "unlearn" to learn (Doz, 1994, p. 101) so as not to be submerged by routine but always to be in a situation to question the dominant logic to get over it and to create or to catch an opportunity.

On the whole, the balance of the stability/dynamic duo (Weick, 1979) stands on its two feet: that of voluntary accumulation, over the long run, of incremental innovations as an organizational capacity to learn or learning how to learn (which is the least imitable aptitude by competitors); that of the deliberate capacity of learning to unlearn.

Cohen and Levinthal (1990) have already shown the importance of having some learning capacities to understand the environment and be involved in the running for innovation. It is here about an even larger aptitude, spread out above the R\&D capacities in the organization but fundamentally of the same nature. Cohen and Levinthal produced a work based on the requirement to get satisfying internal abilities of R\&D to capture environmental knowledge. These abilities are an aptitude and a decisive strategic competency. That is to say, a generic ability of the firm to adapt itself, to evolve and to learn.

The diffusion of knowledge in the organization is a good way to promote exchanges and dialogue, thus creating opportunities to sweep away all the possibilities and build different tracks that could be used to innovate: Nonaka $(1991,1994)$ proposes a systematic approach to the circuit of information and the creation of knowledge which lead to innovation.

One places oneself here in a perspective of innovation, sometimes radical but essentially incremental, in the centre of which plays of actors are situated (at the intra- and inter-organizational interface) around a single product in the framework of a global awareness of the evolution of interacting.

The analysis of the market remains essential above all for the needs which have not been satisfied in the framework of technological paradigms and existing technologies (Henderson and Clark, 1990).

In this perspective, and to follow this logic through, customer satisfaction, besides interfirm cooperation, is also a non-negligible source for innovating (von Hippel, 1976) even if some customers (in particular coming from industry: a "B to B" relationship) can sometimes represent a source of inertia when they turn out to be adverse towards innovations.

The open field on "learning by interacting" (von Hippel, 1976; Lundvall, 1988), requested to explore the link Product Innovation/Consumer(s), remains learning by using the product (whose distant origin is "Learning by Doing", Arrow, 1962). The modern aspect of this question is treated by Harkema and Baets (2001, this issue). 
As a counterpart of these organizational steps forward, fear of failure remains a powerful inhibitory factor and it is then advisable to research methods of venturing at a minimal risk: so that if the trial leads to a failure (which we always learn from) this is not at a prohibitive cost prejudicial later on. Consequently, an approach based on "Satisficing" is required.

The trial must be reasonable to be able to integrate with the strategy as a normal necessity. It is also necessary, on the ground, to generate internally a facility to combine and re-combine information and competencies to try out new challenges transcending the existing routine. The recombining of competencies is not easy in a restricted hierarchical and managerial way unless precisely to promote a culture of exchange, team work and questioning...

Indeed, the principal problem is internal short-sightedness, linking too tightly competencies that need to be satisfied (in the short run): which induces a restricted perception of the market and the constitution of impediments or self-generated blocking-up (Weick, 1979). On the contrary, an over-estimation of the possibilities of the transfer of competencies or of the core business can produce an extremely dangerous and significant gap between what is said and the practices of the business.

Short term efficiency is lessened when one places oneself in a strategy of renewal. However, a suitable economic horizon does not limit itself to the short run (and, all the more so, to short term maximization). The inertia of the employed technologies can only be thought of in the long term and as much to develop them in commercial terms as to build renewal and evolution.

These questions cannot be exclusively elaborated from the internal point of view in so far as firms' challenges within Industrial Organization implies the need for inter-firm cooperation on a complementarity basis (Richardson, 1972) where the question of coordinating legal independent entities tends to be crucial at the very time when interactions take place at an a yet never achieved complexity level.

\section{Conclusion}

We are hoping to bring a stone to the building still under construction. Our choice for this special issue has been to select deliberately contributions which propose angles of approach that are very different and complementary. Authors, whose specialization levels are variable, are capable of thinking about the economy changes and being involved as much on the academic level as on the observation level.

We have also selected papers proposing a model or referring to models since a legitimate approach for searching for alternatives, to be taken seriously, must be like this but not built exclusively and necessarily like this.

One will give here (Sect. 4.1) a presentation of the contributions and also (Sect. 4.2) a possible guide-book for the readers of this special issue.

\subsection{The contributions}

The link between contributions is made up of an exploration of interactions of different natures (between firm and environment, between firms, between firm and consumers) 
and on different levels (local/global, spatial/a-spatial, micro/macro, short run/long run) always in an obvious or tacit contextual and spatial framework and related to selforganization (see above).

The special issue can be presented by three angles:

- that of the sector oriented approach within the framework of Industrial Organization through interactions of individual behavior or through embedded interactions in a historical context and a spatial context;

- that of the organization of temporal interactive building of expectations to innovate while adapting;

- that of the organization of interactions between the firm and its environment to adapt better as well as that of the organization of interactions between the innovating firm and the consumers.

These angles go back, respectively, to different learning types: (4.1.1) implicit learning by taking into account system effects initiated by individual choices versus explicit learning by a set of actors making a collective framework within a given history and a definite space; (4.1.2) learning by the building of temporal marks directing the decision of innovation; (4.1.3) learning by linking permanently narrow relations between the structural organizational variables and the actors around a change and/or an innovation.

\subsubsection{The sector oriented by Industrial Organization on a micro-economic basis and the building up of trajectories}

Auriol and Benaïm (2001, this issue) separate themselves from Arthur (1989) and propose an analysis of spontaneous and endogenous self-organization from analysis of network externalities and of interactions by implicit coordination; Zimmermann (2001, this issue), on the contrary, following Arthur (1989) and coming closer to a SOC type analysis, shows the importance of small historic events, small worlds, territorial anchorage in a territorial dynamic based on the dialectical duo anchorage/nomadism where, whereas the natural movement is nomadism in a context of globalization (not only for the dynamic innovating sectors), this duo structures itself however by positive local inertia linked to particular events and to history in the framework of local/global complementary and dense interactions in a system which is always open.

\subsubsection{The building up of adaptive expectations to innovate}

In a neo-evolutionary paradigm Le Bas's (2001, this issue) proposal is about analyzing the building up process of expectations (in order to manage a firm and innovate) which supports itself by taking into account the set of intra- and inter-organizational interactions. This leads to explain, in an endogenous way, of the stability of expectations concerning technological innovations. The interest of the study of interactions, at this level, is crucial as well as the respective influence of the internal complexity of organizations and the nature of the relationships between organizations. To anticipate depends, at $t_{0}$, on the idea that one has of the future: some have already showed (Knight, 1921; Keynes, 
1936; Simon, 1958 and others) ${ }^{42}$ the importance of the question of the building up of expectations.

It remains to be seen if it is about self-fulfilment prophecies, how the actors coordinate themselves and how uncertainty plays... This is why Simon (1958) emphasized adaptive expectations. Le Bas (2001, this issue) has taken up this idea even though, as everybody knows, it had been strongly criticized by partisans of rational expectations (Lucas and Barro particularly).

\subsubsection{The organization of the firm articulated by its environment characteristics}

- generically with Poncet (2001, this issue) where it is about looking for excluding determinism (linked to polar situations studied) and leading to an understanding related to the theory of catastrophes (Thom, 1980);

- specifically, downstream, in the firm's relationship with its customers thanks to the survey proposed by Harkema and Baets (2001, this issue) following pioneers like von Hippel (1976), Lundvall (1988), Henderson and Clark (1990) and Nonaka (1994).

\subsection{A guide-book for the readers of this special issue}

The context in which firms are evolving today is particularly complex. Current firm strategies are facing major challenges:

- Using external and/or internal competencies (outsourcing on one hand, and internal intensification and development of strategic competencies on the other hand).

- Thanks to core competencies, a narrower scope of activities is supposed to increase benefits, and limit costs as well as to put firms at a higher technological rank. Based on this new organizational frame, each firm still has to arbitrate in terms of innovation between current product(s) and/or new products. Moreover, firms still use strategies of diversification.

- In all cases, a given firm needs strong and quite stable relationships with suppliers (industrial partnerships) and sometimes also has to build alliances (occasionally with rivals).

All this increases the complexity in processing decisions and strategies as well as interactions between strategies on each specific market.

Anyway, the main question is still to know if (small and/or significant) improvements of firms are linked with radical changes or slow adaptive processes; other correlated questions are how to evaluate the frequency of radical changes, how to specify their content and also how to capture the idea of trajectory?

Evolutionism tried to answer these questions with the help of the Darwinian paradigm (and later, with the Lamarckian paradigm). Nobody ignores that Evolutionism was a first qualitative step to move from static towards non-linear and self-organizational dynamic approaches in Economics. However, it was not always very relevant or convincing at

\footnotetext{
${ }^{42}$ Actors can only think about the future, at a given moment $\left(t_{0}\right)$, in conjunction with the idea that they have at $t_{0}$ thanks to a given convention.
} 
individual, inter-individual and organizational levels. By the way, Evolutionism does focus on the fact that a firm's behavior is heavily dependent on previous experience. However, a turbulent environment gives some advantages to firms able to deal with novelty and to undertake radical changes. We can see here one limitation of Evolutionism.

Research on organizational evolution and on organizational ecology gives some insight into demographic processes and on the effects of changing environmental conditions. But it does not pay sufficient attention to the internal emergence of organizational forms and to strategies.

Recently, researchers in economics and management sciences interested in explaining changes were finally more attracted by the complexity approach. Quite a good insight of the possible scope of such an approach has been put forward in a special issue of Organization Science (1999a). This was however done in too general terms to see precisely how to apply it to Economics and Management Sciences; we expect then to be helpful on that topic.

Elements and interactions between elements which are the basis of complexity analysis and of dynamic systems deal with, as far as we are concerned here, individual behaviors and interactions between individuals.

Indeed, thanks to organizational theories, we know that a firm, as such, cannot be taken as an individual (with some exceptions when specific people act in the name of a given firm): this is why intra-organizational analysis of interactions between individuals (individuals as actors) is particularly relevant. However, a firm on a market can easily be taken as an individual facing rivals (i.e. competitors).

To go forward, we suggest the following linked proposals:

$A /$ The basic question (obviously outside of the standard static equilibrium framework) always seems to be the same: how to explain, understand and feature trajectories and changes in trajectories?

$\boldsymbol{B} /$ Whatever the answer is to this first and basic question, trajectory changes (that is to say whatever they are) have huge consequences on organizations and organizational changes...

C/ Organizational changes sometimes imply inertia as well as resisting changes (which is here a topic outside our scope but particularly important and relevant, especially since Weick explained how firms produce their own impediments...).

D/ Environmental changes create opportunities for old and new firms to compete and develop capabilities to manage changes.

$\boldsymbol{E} /$ Organizational and (desired or undergone) strategic changes induce, at each firm level and for a significant part, heterogeneity of firms at a given synchronological time of observation (in the long run, heterogeneity is explained thanks to path dependency, cultural aspects...).

F/ A single firm (or a set of linked firms) is able to initiate (micro/meso/macro) irreversibility thanks to (desired) strategies: that is to say, the role played by micro-decisions having, sometimes and in a more or less large extent, a structural macro effect.

For traditional approaches, it is easy to think in terms of causality $(\rightarrow)$ between these different levels such as: $\mathrm{F} \rightarrow \mathrm{A}$; $\mathrm{B} \rightarrow \mathrm{E}(\mathrm{E}$ and/or $\mathrm{C}) ; \mathrm{D} \rightarrow \mathrm{E}(\mathrm{E}$ and/or $\mathrm{C}) \rightarrow \mathrm{A} \ldots$ 
As we put it here, the frame to be studied is co-evolution and interactions. Therefore, in this introduction, we tried to explore all linkages together: A, B, C, D, E, F...

As a help for readers, we can now say what authors are at first dealing with:

\begin{tabular}{|l|c|c|c|c|c|c|}
\hline & $\boldsymbol{A}$ & $\boldsymbol{B}$ & $\boldsymbol{C}$ & $\boldsymbol{D}$ & $\boldsymbol{E}$ & $\boldsymbol{F}$ \\
\hline Auriol-Benaïm & $\times$ & & & & & $\times$ \\
\hline Zimmermann & $\times$ & $\times$ & $\times$ & $\times$ & & \\
\hline Le Bas & $\times$ & $\times$ & & & $\times$ & $\times$ \\
\hline Poncet & & $\times$ & $\times$ & $\times$ & $\times$ & \\
\hline Harkema-Baets & & & & & & $\times$ \\
\hline
\end{tabular}

We expect that the contributions of these authors will help, implicitly or explicitly, to test hypotheses about linked proposals in the complexity understanding mentioned above.

But as a target for (other) authors for further works, we would mainly like to stress the point on finding tools of recognition and driving change(s) in economics and management sciences: recognition of changes is particularly dedicated to the next potential papers coming from statistical fields and explaining how to feature changes (with the help of statistical tools).

In other words, we think that different types of works and axes are required to look into such types of hypothesis to understand complexity in economics, management sciences and, more generally, social sciences.

Finally, thanks to the European Journal of Economic and Social Systems, we expect that a strong promotion of these quite new fruitful ideas about the complexity approach, embodied in rigorous analysis, stylized facts, models and tools will help economics and management sciences to understand, describe and forecast in a better way what's going on in their own fields.

\section{References}

Akerlof G. (1970) The market for lemons: Quality uncertainty and the market mechanism, Quarterly Journal of Economics, pp. 488-500.

Anderson P. (1999) Complexity theory and organization science, Special issue: Application of complexity theory to organization science, Organization Science, 10 (3), pp. 216-232.

Ansoff H.I. (1965) Corporate Strategy. John Wiley, New York.

Aoki M. (1986) Horizontal vs. vertical information structure of the firm, American Economic Review, No. 5, pp. 971-983.

Aoki M. (1988) Information, incentives and bargaining in the Japanese economy. Cambridge University Press, Cambridge.

Aoki M. (1990) Toward an economic model of the Japanese firm, Journal of Economic Literature, pp. 1-27. 
Aoki M. (1991) Aspects of conventions within the firm, Colloque sur l'économie des conventions, Vol. II: Les Modèles, CREA, André Orléan (Ed.), 39 p.

Argyris C., Schön D. (1978) Organizational learning. Addisson-Wesley.

Arrow K. (1962) The economic implication of learning by doing, Review of Economic Studies, No. 29, pp. 155-173.

Arrow K. (1974) Les limites de l'organisation. P.U.F., Paris.

Arthur B. (1989) Competing technologies, increasing returns and lock-in by historical events, The Economic Journal, 99 (March), pp. 116-131.

Ashby W.R. (1952) Design for a brain. John Wiley, New York.

Ashby W.R. (1958) Requisite variety and its implications for the control of complex systems, Cybernetica, No. 2.

Asanuma B. (1989) Manufacturer-supplier relationships in Japan and the concept of Relationspecific skill, Journal of the Japanese and International Economies, pp. 1-30.

Auriol E., Benaïm M. (2000) Standardization in decentralized economics, American Economic Review, 90 (3), pp. 550-570.

Axelrod R. (1984) The evolution of cooperation. Basic Books, New York.

Baumol W., Willig R. (1981) Fixed costs, sunk costs, entry barriers, and sustainability of monopoly, Quarterly Journal of Economics, pp. 405-431.

Boisot M., Child J. (1999) Organizations as adaptative systems in complex environments, Special issue: Application of complexity theory to organization science, Organization Science, 10 (3), pp. 237-252.

Bouvier-Patron P. (1992) Éléments d'une approche théorique des réseaux d'entreprises, Thèse de doctorat, France.

Bouvier-Patron P. (1993) Les formes d'organisation des entreprises: limites de l'approche transactionnelle et genèse de l'inter-organisation, Économie Appliquée, No. 4.

Bouvier-Patron P. (1994) La dimension inter-entreprises de production dans le modèle J d'Aoki, Revue d'Économie Politique, No. 1.

Bouvier-Patron P. (1995) Asymétrie et symétrie relationnelle dans la relation bilatérale clientfournisseurs, Économies et Sociétés, Sér. W, No. 2.

Bouvier-Patron P. (1996a) La question de la réduction d'incertitude chez F. Knight, L'Actualité Économique, No. 4.

Bouvier-Patron P. (1996b) Un concept de réseau pour analyser l'organisation industrielle. In: Ravix J.L. (Ed.), Coopération entre les entreprises et organisation industrielle, col. Recherche et Entreprise. Éditions du CNRS, Paris.

Bouvier-Patron P. (1998a) Quelle relation possible entre niveau d'aspiration satisfaisant et point focal?, Revue Internationale de Systémique, 12, No. 2.

Bouvier-Patron P. (1998b) Coordination et intelligence relationnelle au sein de l'organisation industrielle, Revue d'Intelligence Économique, No. 3.

Bouvier-Patron P. (1999) Coordination et réduction d'incertitude. In: Baslé M., Delorme R., Lemoigne J.L., Paulré B. (Eds.), Les approches évolutionnistes de la firme et de l'industrie. L'Harmattan, Paris.

Breton A., Wintrobe R. (1982) The logic of bureaucratic conduct, C.U.P. Cambridge

Brown J.S., Duguid P. (1998) Organizing knowledge, California Management Review, 40 (3), pp. 90-111.

Burns T., Stalker G. (1961) The management of innovation. Tavistock, London. 
Caves R.E., Porter M.E. (1977) From entry barriers to mobility barriers: Conjectural decisions and contrived deterrence to new competition, Quarterly Journal of Economics, pp. 241-261.

Chandler A. (1977) The visible hand. Harvard University Press, Cambridge.

Charreaux G. (1987) La théorie positive de l'agence: une synthèse de la littérature. In: De nouvelles théories pour gérer l'entreprise. Economica, Paris, pp. 19-55.

Coase R.H. (1937) The nature of the firm, Economica, pp. 386-405.

Cohen W., Levinthal D. (1990) Absorptive capacity: A new perspective on learning and innovation, Administrative Science Quarterly, pp. 128-152.

Cosnard M. (1991) Dynamique chaotique déterministe. In: Fogelman Soulié F. (Ed.), Les théories de la complexité. Seuil, Paris.

Cournot A. (1838) Recherches sur les principes mathématiques de la théorie des richesses. Marcel Rivière.

Crémer J. (1980) A partial theory of the optimal organization of a bureaucracy, The Bell Journal of Economics, 11 (2).

Crémer J. (1990) Common knowledge and the co-ordination of economic activities. In: Aoki M., Gustafson B., Williamson O. (Eds.), The firm as a Nexus of Treaties. Sage Publishers, London, pp. 53-76.

Crémer J. (1993) Corporate culture and shared knowledge, Industrial and Corporate Change, 2 (3), pp. 351-386.

Crozier M., Friedberg E. (1977) L'acteur et le système. Seuil, Paris.

Cyert R., March J.G. (1963) A behavioral theory of the firm. Prentice Hall, Paramus.

Dalle J.M. (1995) Dynamiques d'adoption, coordination et diversité. La diffusion des standards technologiques, Revue Économique, 46 (4), pp. 1081-1098.

David P.A. (1985) Clio and the economics of QWERTY, American Economic Review, 75 (2), pp. 332-337.

Desreumaux A. (1996) Nouvelles formes d'organisation et évolution de l'entreprise, Revue Française de Gestion, No. 107, pp. 86-108.

Dooley K.J., van de Ven A.H. (1999) Explaining complex organizational dynamics, Special issue: Application of complexity theory to organization science, Organization Science, 10 (3), pp. 358-372.

Dosi G., Teece D.J., Winter S. (1990) Les frontières des entreprises : vers une théorie de la cohérence de la grande entreprise, Revue d'Économie Industrielle, No. 51, pp. 238-254.

Doz Y. (1994) Les dilemmes de la gestion du renouvellement des compétences clés, Revue Française de Gestion, No. 97, pp. 92-104.

Durand T. (2000) L’Alchimie de la compétence, Revue Française de Gestion, No. 127, pp. 84102.

Dussauge P., Garette B., Ramanantsoa B. (1988) Stratégies relationnelles et stratégies d'alliances technologiques, Revue Française de Gestion, No. 68, pp. 7-19.

European Journal of Economic and Social Systems (2000) Neural models in economy and management science, Special issue 14 (1).

Farrell J., Gallini N. (1988) Second-sourcing as a commitment: Monopoly incentives to attract competition, Quarterly Journal of Economics, pp. 673-694.

Farrell J., Saloner G. (1986) Installed base and compatibility, American Economic Review, 76, pp. 940-955.

Farrell J., Scotchmer S. (1988) Partnerships, Quarterly Journal of Economics, pp. 279-297. 
Garette B. (1989) Actifs spécifiques et coopération: une analyse des stratégies d'alliances, Revue d'Économie Industrielle, No. 50, pp. 15-31.

Georgescu-Roegen N. (1971) The entropy law and the economic process. Harvard University Press, London.

Grossman S., Hart O. (1986) The cost and benefits of ownership: A theory of vertical and lateral integration, Journal of Political Economy, 94 (4), pp. 691-719.

Guilhon A. (1998) Le changement organisationnel est un apprentissage, Revue Française de Gestion, No. 120, pp. 98-106.

Hakansson H. (1982) International marketing and purchasing of industrial goods. J. Wiley, New York.

Hakansson H. (1988) Formal and informal cooperative strategies in international networks. In: F. Contractor, P. Lorange (Eds.), Cooperative strategies in international business. Lexington Books, Mass, pp. 369-379.

Hakansson H. (1989) Corporate technological behaviour. Routledge, London.

Hart O., Moore J. (1990) Property rights and the nature of the firm, Journal of Political Economy, pp. 119-1158.

Hayek F.A. (1945) The use of knowledge in society, American Economic Review, No. 4, pp. 519-530.

Henderson R., Clark K.B. (1990) Architectural innovation, Administrative Science Quarterly, 35, pp. 9-30.

Holmstrom B., Tirole J. (1989) The theory of the firm. In: Schmalensee R., Willig R.D. (Eds.), Handbook of industrial organization, Vol. 1. Elsevier Science, pp. 61-133.

Imai K., Itami H. (1984) Interpenetration of organization and market, International Journal of Industrial Organization, pp. 285-310.

Itoh H. (1987) Information processing capacities of the firm, Journal of the Japanese and International Economies, pp. 299-326.

Jacquemin A. (1985) Sélection et pouvoir dans la nouvelle économie industrielle. Economica, Paris.

Jacquemin A. (1988) Coopération entre les entreprises et droit économique. In: Jacquemin A., Remiche B. (Eds.), Coopération entre entreprises. De Boek, Brussels, pp. 17-30.

Katz M.L., Shapiro C. (1985) Network externalities, competition and compatibility, American Economic Review, 75 (June) pp. 424-440.

Kauffman S. (1993) The origins of order. Oxford University Press, New York.

Kauffman S. (1995) The search for law of self organization and complexity. Oxford University Press, New York.

Keynes J.M. (1921) A treatise on probability. Macmillan, London.

Keynes J.M. (1936) The general theory of employment interest and money. Mac Millan, London.

Kimberly J.R., Bouchikhi H. (1995) The dynamics of organizational development and change: How the past shapes the present and constrains the future, Organization Science, 6 (1), pp. 9-18.

Kline S., Rosenberg N. (1986) An overview of innovation. In: Landau R., Rosenberg N. (Eds.), The positive sum strategy. Academy of Engineering Press, pp. 275-305.

Knight F. (1921) Risk, uncertainty and profit. The Riverside Press, Cambridge.

Kreps D. (1990) Corporate culture and economic theory. In: Alt J., Shepsle K. (Eds.), Perspective on positive political economy. Cambridge University Press, Cambridge. 
Kreps D., Wilson R. (1982) Reputation and imperfect information, Journal of Economic Theory, 27, pp. 253-279.

Labourdette A. (1992) Théorie des organisations. P.U.F., Paris.

Laffont J.J. (1985) Théorie des incitations et économie publique, Recherches Économiques et Sociales, No. 11, pp. 171-180.

Lawrence P.R., Lorsch J.W. (1967) Organization and environment: Managing differenciation and integration, Harvard Graduate School of Business Administration, Boston MA.

Lemoigne J.L. (1990) La modélisation des systèmes complexes. Dunod, Paris.

Lundvall B.A. (1988) Innovation as an interactive process. In: Dosi G. et al. (Eds.), Technical change and economic theory. Pinter Publishers.

March J., Simon H. (1958) Organizations. John Wiley, New York.

Ménard C. (1990) L'Économie des organisations. La Découverte, Paris.

Meyer H.D. (1995) Organizational environments and organizational discourse: Bureaucracy between two worlds, Organization Science, 6 (1), p. 33-43.

Miles R.E., Snow C.C. (1978) Organization strategy, structure and process. Mc Graw-Hill.

Miles R.E., Snow C.C. (1992) Causes of failures in network organizations, California Management Review, 34 (4), pp. 53-72.

Milgram S. (1967) The small world problem, Psychology Today, No. 2, pp. 60-67.

Milgron P., Roberts J. (1982) Predation, reputation, and entry deterrence, Journal of Economic Theory, 27, pp. 280-312.

Mintzberg H. (1979) The structuring of organizations. McGraw Hill.

Morel B., Ramanujam R. (1999) Through the looking glass of complexity: The dynamics of organizations as adaptative and evolving systems, Special issue: Application of complexity, theory to organization science, Organization Science, 10 (3), pp. 278-293.

Nelson R.R., Winter S.G. (1982) An evolutionary theory of economic change. The Belknap Press of Harvard University Press.

Nonaka I. (1991) The knowledge-creating company, Harvard Business Review, NovemberDecember, pp. 96-104.

Nonaka I. (1994) A dynamic theory of organizational knowledge creation, Organizational Science, 5 (1), pp. 14-37.

Organization Science (1999a) Special issue, Application of complexity theory to organization science, 10 (3).

Organizational Science (1999b) Special issue, Co-evolution, 10 (5).

Paulré B. (1993) Apprentissage et systémique, Économies et Sociétés, Sér. W, No. 1, pp. 25-61.

Paulré B. (1997) Évolutionnisme contemporain et auto-organisation, Économie Appliquée, No. 3.

Paulré B. (Ed.) (1998) Épistémologie de la stratégie en économie. Publications de la Sorbonne, Paris.

Paulré B. (1999a) Approches évolutionnistes de la firme et de l'industrie, Baslé M., Delorme R., Lemoigne J.L., Paulré B. (Eds.). L'Harmattan, Paris.

Paulré B. (1999b) Presentation of the EJESS, European Journal of Economic and Social Systems, 13 (1).

Penrose E. (1959) The theory of the growth of the firm. Oxford Blackwell.

Polanyi M. (1966) The tacit dimension. DoubleDay Anchor, New York. 
Porter M. (1979) The structure within industries and companies performance, Review of Economics and Statistics, No. 2, pp. 214-227.

Porter M. (1985) Competitive advantage. The Free Press, New York.

Powell W. (1990) Neither market nor hierarchy: Network forms of organization, Research In Organization Behavior, 12, pp. 295-336.

Prahalad C.K., Hamel G. (1990) The core competence of the corporation, Harvard Business Review, No. 3, pp. 79-91.

Prigogine I., Stengers I. (1979) La nouvelle alliance. Gallimard, Paris.

Radner R. (1992) Hierarchy: The economics of managing, Journal of Economic Literature, pp. 1392-1415.

Richardson G.B. (1972) The organisation of industry, Economic Journal, pp. 883-896.

Ring P., van de Ven A. (1992) Structuring cooperative relationships between organizations, Strategic Management Journal, 13, pp. 483-498.

Ring P., van de Ven A. (1994) Developmental processes of cooperative interorganizational relationships, Academy of Management Review, 19 (1), pp. 90-118.

Riordan M. (1990) What is vertical integration? In: The firm as a nexus of treaties. In: Aoki M., Gustafson B., Williamson O. (Eds.). Sage publications, London, pp. 94-111.

Rojot J. (1994) La négociation. Vuibert, Paris.

Rosenberg N. (1982) Inside the black box. Cambridge University Press, Cambridge.

Rosnay J. de (1975) Le macroscope. Seuil, Paris.

Sappington D. (1991) Incentives in principal-agent relationships, Journal of Economic Perspectives, 5 (2), pp. 45-66.

Saviotti P. (1996) Technological evolution, variety and the economy. E. Elgar Publishing.

Schelling T. (1956) An essay on bargaining, American Economic Review, pp. 283-306.

Schelling T. (1960) The strategy of conflict. Harvard University Press, Cambridge.

Schotter A. (1981) The economic theory of social institution. Cambridge University Press, Cambridge.

Selten R. (1978) The chain-store paradox, Theory and Decision, 9, pp. 127-159. In: Models of strategic rationality, Selten, 1988. Kluwer Academic Publishers, Dordrecht, pp. 33-65.

Shackle G. (1979) Imagination and the nature of choice. Edimburg University Press, Midlothian.

Shackle G.L. (1961) Decision, order and time in human affairs. Cambridge University Press, Cambridge.

Simon H. (1947) Administrative behavior. Macmillan, New York.

Simon H. (1955) On class of skew distribution functions, Biometrika, 52.

Simon H. (1958) The role of expectations in an adaptative or behavioristic model. In: Models of bounded rationality, 1982. The MIT Press, Cambridge, pp. 380-399.

Simon H. (1979) Rational decision making in business organizations, American Economic Review, pp. 493-513.

Simon H. (1980) The sciences of the artificial. The MIT Press, 2nd edition, Cambridge.

Simon H. (1982) Models of bounded rationality, 2, The MIT Press, Cambridge.

Simon H. (1991) Organizations and markets, Journal of Economic Perspectives, No. 2, pp. $25-$ 44.

Simon H. (1993) Altruism and economics, American Economic Review, (May, A.E.A.) pp. 156161. 
Teece D.J. (1980) Economies of scope and the scope of the enterprise, Journal of Economic Behavior and Organization, pp. 223-247.

Teece D.J. (1988) Technological change and the nature of the firm. In: Dosi G. et al. (Eds.), Technical change and economic theory. Pinter Publishers, pp. 256-281.

Thiétart R.A., Koenig C. (1987) Programmes aérospatiaux: la stratégie de l'organisation mutuelle, Revue Française de Gestion, No. 62, pp. 42-53.

Thiétart R.A., Forgues B. (1993) La dialectique de l'ordre et du chaos dans les organisations, Revue Française de Gestion, No. 93, pp. 5-15.

Thiétart R.A., Forgues B. (1995) Chaos theory and organization, Organization Science, 6 (1), pp. 19-31.

Thom R. ( 1980) Paraboles et catastrophes. Flammarion, Paris.

Thorelli H.B. (1986) Networks: Between markets and hierarchies, Strategic Management Journal, pp. 37-51.

Von Hippel E. (1976) The dominant role of users in the scientific instrument innovation process, Research Policy, No. 5, pp. 212-225.

Weick K.E. (1977) Organization design, Organizational Dynamics, 6, pp. 31-46.

Weick K.E. (1979) The social psychology of organizing. Addisson-Wesley.

Weisbuch G. (1991) Complex system dynamics. Addisson-Wesley, Reading MA.

Wenger E.C., Snyder W.M. (2000) Communities of practice, Harvard Business Review, January, pp. 139-145.

Wernerfelt B. (1984) A resource based view of the firm, Strategic Management Journal, No. 5, pp. 171-180.

Williamson O. (1975) Markets and hierarchies: Analysis and antitrust implications. The Free Press, New York.

Williamson O. (1985) The economic institutions of capitalism. The Free Press, New York.

Zimmermann J.B., Steyer A. (1996) Externalités de réseau et adoption d'un standard dans une structure résiliaire, Revue d'Économie Industrielle, No. 76.

To access this journal online: www.edpsciences.org 